\title{
Consumer Value and Lifestyle as A Predictor of Herbal Medicine Purchase Intention in Surakarta-Indonesia
}

\author{
Purwoko $^{1} \&$ Tony Wijaya ${ }^{2}$ \\ ${ }^{1}$ Faculty of Economic and Business, Universitas Ahmad Dahlan, Indonesia \\ ${ }^{2}$ Faculty of Economic, Universitas Negeri Yogyakarta, Indonesia \\ Correspondence: Tony Wijaya, Faculty of Economic, Universitas Negeri Yogyakarta, Jl. Colombo No 1 \\ Karangmalang, Indonesia. E-mail: tony@uny.ac.id
}

\author{
Received: October 2, 2018 Accepted: February 25, 2019 Online Published: March 15, 2019 \\ doi:10.5539/gjhs.v11n4p69 URL: https://doi.org/10.5539/gjhs.v11n4p69
}

\begin{abstract}
This study aims to examine the influence of consumer values and lifestyles partially or simultaneously to the purchase intention of herbal medicine in Surakarta-Indonesia. The type of this research is survey research. This study uses primary data collected using questionnaires. The population in this study were consumers who consumed various types of herbal medicine in Surakarta-Indonesia. The sampling technique used was purposive, respondents who already had experience in herbal medicine and had the goal of consuming herbs for personal gain. Techniques of data analysis in this study are to use multiple linear regression analysis. Based on data analysis, it can be concluded that consumer and lifestyle values partially or simultaneously have a significant effect on the intention of herbal medicine purchase in Surakarta-Indonesia. This means the higher the consumer value and lifestyle orientation of the consumer the higher the intention of the purchase of herbal medicine in Surakarta-Indonesia, on the contrary, the lower the consumer value and lifestyle of the consumer the lower the intention of the purchase of herbal medicine in Surakarta-Indonesia.
\end{abstract}

Keywords: lifestyle, consumer value, intention, herbal medicine

\section{Introduction}

Complementary and alternative medicine is common in both developing and developed countries (Aydin et al., 2008; Ekor, 2014). Traditional medicine has a very long history, it's a total practice based on theory, beliefs and experiences, often unexplained, diagnosis, improvement, and treatment of diseases. Herbal medicine has become a well-known form of health service; Although there are some differences between herbal and conventional pharmacological treatments, herbal medicines need to be examined for efficacy using traditional ingredients and certain herbal extracts have proven efficacious for certain conditions (Firenzuoli \& Gori, 2007). Asian countries have a long history of using traditional herbal medicines to manage various medical conditions. A multiethnic study reports that almost $50 \%$ of Asians have consumed one or more herbal products for their health. In Asian countries, medicinal plants and their preparations can be easily accessed from shops and homeopathic stores. Herbs can also be obtained as unregulated food products that do not go through the process of regulating standards (Ahmed et al., 2017).

Herbs/plants, the main component of traditional maternal medica in the world, are life forms on the earth. It's estimated that there are around 350,000 species of plants available (including seed plants, bryophytes, and ferns). Herbal medicines are also referred to as botanical medicines. It makes use of herbs for a therapeutic or medicinal purpose (Nirmal et al., 2013). Herbal formulations evolve from thousands of years of experience in practicing herbal medicine. While therapeutic interventions that use many drugs in modern medicine are based on an understanding of disease processes and mechanisms, the use of multicomponent herbal formulas is based on theory and practical experience. In Chinese herbal medicine, there are 11,146 different types of plants, 1,581 types of animal and insect parts, 80 types of mineral medicine, and more than 50 types of raw chemical preparations, as well as 5,000 (total one million) clinically validated herbs (Pan et al., 2014).

Development of herbal medicine in Indonesia is still considered quite open. However, until now there is no bridge that facilitates the optimal development of herbal medicine between the world of scholarship (academic) with industry and society. In fact, today, harmonization of herbal medicine at the Association of South East Asia 
Nations level is absolutely done if Indonesia does not want to miss compete with overseas herbal products that have been free entry into this country. Harmonization of the Association of South East Asia Nations level to herbal medicine product is absolutely necessary if Indonesia does not want to lose compete with outside products that have been free entry.

In the herbal medical industry major products include dietary supplement, to improve their fatty acids profiles; foods and beverages with added bioactive ingredients (Nirmal et al., 2013). Resources of herbal medicine in Indonesia is quite good. For the people of some area in Indonesia like Java and Madura, traditional medicine better known as herbal medicine (namely Jamu), both in the form of chopped or powder form ready to brew. Written information about herbal medicine which until now well maintained in Surakarta Palace Library is Kawruh and Centini fiber. Kawruh fibers provide systemic information about herbal medicine, containing 1734 ingredients made from natural materials and how to use them and equipped with spells. Local wisdom in other areas such as the Sundanese community has 188 types of medicinal plants of Riau and Jambi provinces known to have 45 herbs with 195 species of medicinal plants have been used by the traditional Melayu tribe community, and 58 herbs with 115 species used by Talang Mamak tribe in Indonesia.

The use of medicinal plants has long been recognized by people with different historical backgrounds and cultures. It can't be denied that medicinal plants have been very helpful in the field of health well before the discovery of modern medicine to date. For a long time, the people of Indonesia use medicinal plants to promote health, restore health, prevention of disease and healing. The use of Indonesian herbal medicine is familiar and always associated with medicinal plants, although herbs can also come from minerals and from animals. There are several kinds of herbs formula that is famous in Indonesia for rheumatic drugs, ringworm, body freshener, young guava leaves for diarrhea, saga leaves and seeds for heartburn.

The pharmaceutical and food industries, traditional or alternative practitioners, users of traditional or household medicine, the cosmetics industry and taste and many more need these plant (Nirmal et al., 2013). Many foreign natural products are listed in Indonesia as food supplements. It is no exaggeration to say that the increasing number of foreign natural medicinal products entering Indonesia is a threat to the national natural medicine drug industry. To face the threat, Indonesia must build a strong national commitment so that all potentials can be managed professionally to achieve the national common goals to improve the competitiveness of national products and industries in the field of natural medicines.

Herbal medicinal products are getting global importance because of its health benefits (Nirmal et al., 2013). The use of plants for medicine has its own charm. The attraction is that the use of medicinal plants other than cheap, also more natural than synthetic drugs. However, it should be noted that the use of medicinal plants is not completely independent of side effects. This can happen given that the research of medicinal plants is still very little, especially concerning how to use to appropriate dosage. Researches aimed at minimizing hazard risks should always be done in order to enlarge the benefits gained. Another reason to use medicinal plants because of the many options and freedoms. When a person struggles against his illness, some of the options given to modern medicine are not very attractive (such as expensive and painful treatment, and the sheer chance of healing), this is different from the crops that have many choices and have psychological appeal.

The concept of herbal medicine has social value because personal choice is influenced by personal values and values recognized by the social environment (Fotopoulos \& Krystallis, 2002). Consumer value and lifestyle are psychographic variables that become the company's orientation in identifying consumer segmentation for health products (Engel et al., 2005; Fraj \& Martinez, 2006). Consumer values and lifestyle are often used by identifying consumer behavior for marketing purposes. Values are considered as an important variable in understanding consumer behavior because values present the fundamental goals that consumers seek, and ultimately for the satisfaction of their segments. The growth in demand for health products such as herbal medicine is driven by the growth of consumer segments that lead to a healthy lifestyle (Divine \& Lepisto, 2005). Several studies have revealed a positive relationship between consumer value and lifestyle with the consumption of health products (Fraj \& Martinez, 2006).

The value as something more desirable must be distinguished from that which is only 'desirable'. Something 'more desirable' affects the selection of various behavioral modes that individuals may have or affect the choice of final behavioral goals (Kluckhohn in Rokeach, 1973). This 'more desirable' has a greater influence in directing behavior, and thus the value becomes composed of the degree of importance. As it is formed, values also have certain characteristics to change. This is because values are obtained in a separate way, which is generated by the cultural, community and personal experience embodied in the individual's psychological structure, then the value becomes durable and stable (Rokeach, 1973). Values have a tendency to settle, though they may still change by certain 
things.

An important issue to consider in the understanding of values is that a person's value can be the same as everyone else's, equal to some, or unlike all others. The definition of value according to Kluckhohn illustrates that values other than to represent the uniqueness of individuals can also represent a particular group. This begins to lead to a universal understanding of values. In its development, Rokeach (1973) stated that the basic assumption of the concept of value is that everyone, everywhere, has the same values as different degrees (denoting affirmations of the universality of values). The most comprehensive research on universal values (in the sense of being anywhere in all cultures) was started by Schwartz and Bilsky (1987).

Value theory according to Schwartz and Bilsky (1987), although still based on previous theories of Rokeach (1973), but shows a significant difference. Schwartz's theory of values, taking into account criticisms of Rokeach's theories overlap one value with another, even between the terminal and instrumental values. Schwartz has been categorizing into a number of value types, where the category has been tested conceptually and statistically. Schwartz has also devised such a structure of values specifically and comprehensively so that one's value can be placed into the map of values. Unlike Rokeach who calls value as a system, it does not explain much about the relationship and the nature of the system.

Schwartz's research on the value of one of them aims to solve the problem of whether human values can be grouped into several value types. Each of these types consists of a number of more specific values. Each type of value is a separate motivational area that plays a role in motivating a person to behave. Schwartz also calls this type of value a motivational type of value. Values act as standards that direct behavior and culture belief also influenced buying intention (Ismail \& Mokhtar, 2015). The value guides the individual to enter a situation and how the individual behaves in the situation (Rokeach, 1973; Homer \& Kahle, 1988). Values become the criteria held by individuals in choosing and deciding things (Homer \& Kahle, 1988) including consumer behavior shaped through values that consumers believe.

Lifestyle has a contribution to behavior on herbal medicines. Some studies consider lifestyle related to herbal medicines such as Arentz et al., (2017), Issa and Basheti (2017) and Lee and Jo (2017). Lifestyle is the style of a person in the world expressed in activities, interests, and opinions (Kotler, 2006). Lifestyle is defined as the pattern of living people who spend time and money on certain activities and are contemporary and comprehensive (Engel et al., 2005). Lifestyle describes the whole person who interacts with his environment. Compared to relatively stable values, lifestyles tend to change more quickly. According to Engel et al., (2005), market researchers who adopt a lifestyle approach tend to classify consumers based on the concept, namely activity (activity), interest (interest), and opinion (opinion).

Consumer consumption activities are expressed in health-promoting activities, interests, and opinions such as balanced living, caring and health care (Magistris \& Gracia, 2008). The lifestyle of healthy consumption is measured by activity indicators, interests and opinions on healthy consumption orientation. Bloch (1984) defines the lifestyle of healthy consumption as an orientation to the prevention of health problems and maximizes personal well-being through consumption patterns. The lifestyle of healthy consumption can be defined as a sense of consumption activity expressed in health-oriented activities, interests, and opinions for the well-being of life.

Some herbal products in Surakarta-Indonesia have penetrated in the domestic market. The development of herbal medicine in Surakarta-Indonesia is inseparable from the role of Surakarta culture which is an ancestral heritage that is still useful to date. Along with the development of time, culture and ancestral heritage such as the use of herbal medicine began to fade. Herbal medicine seems old-fashioned or outdated and consumed by the older generation. Further surveys on the intentions of herbal medicinal use are important as part of further information gathering along with factors that play a role in explaining the intentions of using herbal medicines. Practically low intentions of herbal medicine purchase in Indonesia but some areas are known for their potential herbal resources and the importance of herbal medicine in Indonesia is a problem that needs to be followed through research. Based on the problems of the practical and theoretical, the main purpose of this study to examine the influence of the consumer value and lifestyle on the consumer intention of the purchase of herbal medicine in Surakarta-Indonesia.

\section{Method}

The research is survey research. This study uses primary data collected using questionnaires. Primary data needed in this research is consumer value, lifestyle, and intention of herbal medicine purchase. Instruments are prepared based on preliminary studies conducted by researchers. The population in this study are consumers who use or have used various types of herbal medicine in Surakarta-Indonesia. The sampling technique used is purposive, namely consumer who already had experience in herbal medicine and had the goal of consuming herbs for 
personal gain. Before performing data analysis, research data first tested the validity and reliability of research data. Validity test in this research using the factor analysis method while reliability test using Cronbach Alpha with statistical tool SPSS for Windows. Based on the results of the validity test is known that all items statement in the variable research valid with the factor loading ranges from 0.62 to 0.81 . Based on the reliability test using Cronbach Alpha, all the variables collected through research instruments are reliable because Alpha ranges from 0.73 to 0.85 greater than 0.6 . Techniques of data analysis in this study are to use multiple linear regression analysis.

\section{Results}

\subsection{Characteristics of Respondents}

Respondents in this study can be categorized into several characteristics of respondents, namely by gender, age, and monthly income. The following description is an explanation of the respondent's demographic characteristics. The composition of respondents by gender is as follows:

Table 1. Respondent by Gender

\begin{tabular}{llll}
\hline Gender & Frequency & Percentage & Purchase Intention \\
\hline Male & 75 & $30 \%$ & 2,71 (Middle) \\
Female & 173 & $70 \%$ & 3,61 (High) \\
Total & 248 & $100 \%$ & 3,16 (High) \\
\hline
\end{tabular}

Sources: Primary Data, 2017.

From the table above can be identified that of the total 248 respondents in this study, the number of male respondents is 75 respondents or $30 \%$, while the number of female respondents is 173 respondents or $70 \%$. The composition shows the sex ratio of consumers dominated by women who prioritize herbal medicine in this study. Based on the mean it is known that the purchase intention of female consumers is in the high category $(3,61)$.

\subsection{Characteristics of Respondents by Age}

Data of respondents by age can be seen in the table below.

Table 2. Respondent by age

\begin{tabular}{llll}
\hline Ages (year) & Frequency & Percentage & Purchase Intention \\
\hline $21-25$ & 20 & $8 \%$ & 2,87 (Middle) \\
$26-30$ & 22 & $9 \%$ & 2,81 (Middle) \\
$31-40$ & 68 & $27 \%$ & 2,85 (Middle) \\
$>40$ & 138 & $56 \%$ & 3,92 (High) \\
Total & 248 & $100 \%$ & 3,11 (High) \\
\hline
\end{tabular}

Sources: Primary Data, 2017.

From the table above can be identified that the respondents aged $21-25$ years amounted to 20 people (8\%), aged 26-30 years amounted to 22 people (9\%), aged 31-40 years amounted to 68 people (27\%), aged over 40 years amounted to 138 people (56\%). Thus the majority of consumers aged 40 years and above or adults who care about natural health. Based on the mean it is known that the purchase intention of consumers by age is in the high category $(3,92)$ on above 40 years.

\subsection{Characteristics of Respondents by Income}

The composition of respondents by income level is as follows: 
Table 3. Respondent by income

\begin{tabular}{llll}
\hline Income (IDR) & Frequency & Percentage & Purchase Intention \\
\hline $750.000-2.000 .000$ & 18 & $7 \%$ & 3,94 (High) \\
$2.001 .000-4.000 .000$ & 119 & $48 \%$ & 2,86 (Middle) \\
$4.001 .000-6.000 .000$ & 78 & $32 \%$ & 2,82 (Middle) \\
$>6.000 .000$ & 33 & $13 \%$ & 2,81 (Middle) \\
Total & 248 & $100 \%$ & 3,11 (High)
\end{tabular}

Sources: Primary Data, 2017.

From the table above can be identified that the respondents who have income Rp. 750.000-2,000,000 as many as 18 respondents or by 7\%. Respondents with income of Rp. 2,001,000-4,000,000 as many as 119 respondents or by $38 \%$. Respondents with income of Rp. 4,001,000 - 6,000,000 as many as 78 respondents or by $32 \%$. Respondents who have income above Rp. 6000,000 as many as 33 respondents or by $13 \%$. Thus the majority of respondents in this study are consumers who have income Rp. 2,001,000 - 4,000,000. Based on the arithmetic mean it is known that the purchase intention of consumers by income is in the high category $(3,94)$ on the low-income class.

\subsection{Data Analysis}

Analysis of the effect of consumer value and lifestyle variables on the intention of using herbal medicine as follows:

Table 4. Regression analysis result

\begin{tabular}{llll}
\hline Variable & Beta & t-value & Probability \\
\hline Constanta $(\alpha)$ & 4,937 & 5,797 & 0.000 \\
Consumer value (CV) & 1,328 & 20,537 & 0.000 \\
Lifestyle (LS) & 0,596 & 14,879 & 0.000 \\
\hline
\end{tabular}

$\mathrm{F}=210,991 ;$ Sig $\mathrm{F}=0.000 \mathrm{R}^{2}=0.813$;

Sources: Primary Data, 2017.

From the table above can be formulated a regression equation influence consumer value and lifestyle to intention of purchase of herbal medicine as follows:

$$
\begin{array}{ll}
\mathrm{Y} & =4,937+1,328 \mathrm{CV}+0,596 \mathrm{LS} \\
\mathrm{Y} & =\text { Intention of herbal medicine purchase } \\
\mathrm{CV} & =\text { Consumer value } \\
\mathrm{LS} & =\text { Lifestyle }
\end{array}
$$

From the regression equation, it can be known that the value of consumer constants of 4.937 means the intention of the purchase of herbal remedies remain as big as 4.937 although not influenced by the variable of consumer value and lifestyle. Variable consumer value has a coefficient of 1.328 which means consumer value variables have a positive relationship with the intention of using herbal medicine. This means the higher the value of the consumer the higher the intention of herbal medicine purchase. Conversely, the lower the value of the consumer the lower the intention also the purchase of herbal medicine.

Lifestyle variables have a coefficient of 0.596 which means lifestyle variables have a positive relationship with the intention of using herbal medicine. This means that the higher the lifestyle, the higher the intention of using herbal medicine. Conversely, the lower the lifestyle, the lower the intention of herbal medicine. To test the effect of consumer value $(\mathrm{CV})$ on the intention of using herbal medicine $(\mathrm{Y})$ with probability 0.000 of t-test so it can be concluded that variable of consumer value has positive affect significantly to the intention of herbal medicine usage. To test the influence of lifestyle variable (LS) on the intention of using herbal medicine (Y) with probability 0.000 of t-test so it can be concluded that lifestyle variable has positive affect significantly to the intention of herbal medicine purchase.

To test the effect of consumer value variable and lifestyle simultaneously on the intention of using herbal medicine (Y) with probability value 0.000 of F-test, so it can be concluded that the variable of consumer value and lifestyle simultaneously have a significant positive effect on the intention of herbal medicine purchase. The amount of 
variable change in the intention of herbal medicine purchase is explained by consumer value and lifestyle of $81,3 \%$ $\left(\mathrm{R}^{2}=0,813\right)$ while another variable explaining the intention of herbal medicine besides consumer value and lifestyle is $19,7 \%$.

\section{Discussion}

Based on data analysis, it can be concluded that consumer value and lifestyle partially influence the intention of herbal medicine purchase in Surakarta-Indonesia. This means the higher the consumer value and lifestyle of the consumer the higher the intention of the purchase of herbal medicine in Surakarta-Indonesia, on the contrary, the lower the consumer value and lifestyle of the consumer the lower the intention of the purchase of herbal medicine in Surakarta-Indonesia. Consumer values and lifestyle simultaneously affect the intention of the purchase of herbal medicine in Surakarta-Indonesia. The findings of this study are consistent with the findings of Dreezens et al., (2005); Chen (2009) and Suprapto and Wijaya (2012). The findings indicate that the higher the value that consumers believe the better the evaluation of consumption is done so that the intention of buying is also greater. Herbal products are elements of an individual belief system and are shaped through a value relationship with consumer behavior. Lifestyle is an important part of segmentation because lifestyle depicts patterns of daily consumer behavior. Health-oriented lifestyles tend to prioritize the consumption patterns of natural products (Suprapto \& Wijaya, 2010) such as herbal remedies.

The high level of awareness and knowledge of the importance of health drives the level of consumption of herbal medicines. Surakarta as part of Java Island are pioneers of herbal medicines in Indonesia. Customers obtain their knowledge primarily from the herbalists (Issa \& Basheti, 2017). The value that developed from the Surakarta city from ancient times has paid attention to health problems from natural herbal ingredients. This value has been built by the Surakarta community for a long time which is hereditary. This fits the concept of value from Schwartz that values will form certain behaviors in this case using herbal medicine. Doods et al. (2014) has found that consumer value is relevant to consumers perceptions of the health. The tendency of health-oriented lifestyles to be an important part of the lives of people who avoid chemical drugs. Chemical drugs bring negative effects that encourage the use of natural or herbal ingredients that have a smaller impact. Herbal therapies are increasingly being used around the world because they are perceived to be free of side effects (Sekhri et al., 2013). Special attention to the importance of herbal ingredients has been the concern of the local government who helped support the production of herbal medicines through research and development. To get natural medicine ingredients is easier than chemicals. Some manufacturers of herbal ingredients try to develop the growth of herbal ingredients from nature. All ingredients are easily developed and available in nature.

Based on the conclusions obtained from the data analysis, the authors provide advice for herbal medicine companies to pay attention to the value and lifestyle in preparing the segmentation of herbal products. Companies can socialize a healthy lifestyle by providing health-related information, consumer education about naturalness and herbal benefits through formal and informal media such as health magazines and health talk shows. Limitations in this study in the form of respondents depending on the understanding of the items listed in the questionnaire so that the possibility of differences occur with the measurement of respondents who are self-reported so that the possibility of respondents answered that is not in accordance with the reality itself.

\section{Competing Interests Statement}

The authors declare that there are no competing or potential conflicts of interest.

\section{References}

Ahmed, M., Hwang, J. H., Choi, S., \& Han, D. (2017). Safety classification of herbal medicines used among pregnant women in Asian countries: a systematic review. BMC Complementary and Alternative Medicine, 17, 489. https://doi.org/10.1186/s12906-017-1995-6

Arentz, S., Smith, C. A., Abbott, J., Fahey, P., Cheema, B. S., \& Bensoussan, A. (2017). Combined lifestyle and herbal medicine in overweight women with polycystic ovary syndrome (PCOS): A randomized controlled trial. Phytotherapy Research, 31(9), 1330-1340. https://doi.org/10.1002/ptr.5858

Aydin, S., Bozkaya, A. O., Mazicioglu, M., Gemalmaz, A., Ozacakir, A., \& Ozturk, A. (2008). What influences herbal medicine use? Prevalence and related factors. Turkish Journal of Medical Sciences, 38(5), 455-463.

Bloch, P. (1984). The wellness movement: Imperatives for healthcare marketers. Journal of Health Care Marketing, 4, 9-16.

Chen, T. B., \& Chai, L. T. (2010). Attitude towards the environment and green product: A consumer perspective. Management Science and Engineering. 4(2), 27-39. http://dx.doi.org/10.3968/j.mse.1913035X20100402.002

Divine, R. L., \& Lepisto, L. (2005). Analysis of healthy lifestyle consumer. Journal of Consumer Marketing, 22(5), 
275-283. https://doi.org/10.1016/j.foodhyd.2008.07.004

Doods, S., Murphy, A. J., \& Bulmer, S. (2005). Consumer value in complementary and alternative medicine (CAM) health care service s. Australasian Marketing Journal, 22 (3), 218-229. https://doi.org/10.1016/j.ausmj.2014.08.004

Dreezens, E., Martijn, C., Tenbult, P., Kok, G., \& de Vries, N. K. (2005). Food and values; an examination of values underlying attitudes toward genetically modified and organically grown food products. Appetite, 44(1), 115-122. https://doi.org/10.1016/j.appet.2005.03.005

Ekor, M. (2014). The Growing Use of Herbal Medicines: Issues Relating to Adverse Reactions and Challenges in Monitoring Safety. Frontiers in Pharmacology, 4(177), 1-10. https://doi.org/10.3389/fphar.2013.00177

Engel, J. F., Roger, D. B., \& Paul, W. M. (2005). Consumer behavior (10th ed.). Forth Worth: Dreyden Press.

Firenzuoli, F., \& Gori, L. (2007). Herbal Medicine Today: Clinical and Research Issues. eCAM, 4(S1), 37-40. https://doi.org/10.1093/ecam/nem096

Fotopoulos, C., \& Athanasios, K. (2002). Purchasing motives and profile of the Greek organic consumer: A countrywide survey. British Food Journal, 104, 730-765. https://doi.org/10.1108/00070700210443110

Fraj, E., \& Martinez, E. (2006). Environmental values and lifestyles as determining factors of ecological consumer behaviour: An empirical analysis. Journal of Consumer Marketing, 23(3), 113-144. https://doi.org/10.1108/07363760610663295

Homer, P. M., \& Khale, L. R. (1988). A structural equation test of the value-attitude-behavior hierarchy. Journal of Personality and Social Psychology, 54, 638-646. https://doi.org/10.1037/0022-3514.54.4.638

Ismail, S., \& Mokhtar, S. S. M. (2015). The antecedents of herbal products actual purchase in Malaysia. Management Science Letters, 5, 771-780. https://doi.org/10.5267/j.msl.2015.5.011

Issa, R., \& Basheti, I. (2017). Herbal medicine use by people in Jordan: Exploring believes and knowledge of herbalists and their customers. Trends in Medical Research, 12(2), 55-64. https://doi.org/10.3923/tmr.2017.55.64

Kotler, P. (2006). Marketing Management, Millennium Edition. New Jersey: Prentice Hall International, Inc.

Magistris, T., \& Gracia, A. (2008). The decision to buy organic food products in Southern Italy. British Food Journal, 10 (9), 929-947. https://doi.org/10.1108/00070700810900620

Nirmal, S. A., Pal, S. C., Otimenyin, S. O., Aye, T., Elachouri, M., Kundu, S, K., Thandavarayan, R. A., \& dMandal, S. C. (2013). Contribution of herbal products global market. The Pharma Review, 95-104.

Lee, J. H., \& Jo, J. (2017). Successful treatment with Korean herbal medicine and lifestyle management in an obese woman with polycystic ovarian syndrome: a case report. Integrative Medicine Research, 6(3). https://doi.org/10.1016/j.imr.2017.06.002

Pan, S., Litscher, G., Gao, S., Zhou, S., Yu, Z., Chen, H., Zhang, S., Tang, M.., Sun, J., \& Ko, K. (2014). Historical Perspective of Traditional Indigenous Medical Practices: The Current Renaissance and Conservation of Herbal Resources. Evidence-Based Complementary and Alternative Medicine. https://doi.org/10.1155/2014/525340

Rokeach, M. (1973). The nature of human values. NewYork: The Free Press. https://doi.org/10.1093/sf/53.4.659

Schwartz, S. H., \& Bilsky, W. (1987). Towards universal psychological structure of human values. Journal of Personality and Social Psychology, 53, 550-562. https://doi.org/10.1037/0022-3514.53.3.550

Sekhri, K., Nandha, R., \& Bhanwra, S. (2013). Herbal products: a survey of students' perception and knowledge about their medicinal use. International Journal of Basic \& Clinical Pharmacology, 2(1), 71-76. https://doi.org/10.5455/2319-2003.ijbcp20130114

Suprapto, B., \& Wijaya, T. (2012). Intention of Indonesian consumers on buying organic food. International Journal of Trade, Economics, and Finance, 3(2), 114-119. https://doi.org/10.7763/IJTEF.2012.V3.183

\section{Copyrights}

Copyright for this article is retained by the author(s), with first publication rights granted to the journal.

This is an open-access article distributed under the terms and conditions of the Creative Commons Attribution license (http://creativecommons.org/licenses/by/4.0/). 